\title{
User Experience Specification through Quality Attributes
}

\author{
Llúcia Masip, Marta Oliva, and Toni Granollers \\ Dept. de Informática e Ingeniería Industrial, \\ Universidad de Lleida, \\ 25001, Lleida \\ \{lluciamaar, oliva, tonig\} @diei.udl.cat
}

\begin{abstract}
The concept of user experience includes different facets which have still not reached a consensus. On the other hand, the ISO/IEC 25010:2011 standard shows a structured quality model which permits us to obtain quality systems and software. The main aim is the specification of user experience based on the facets which are implicitly considered in the standard.
\end{abstract}

Keywords: User experience, facets, ISO, quality systems and software.

\section{Introduction}

Recently, the User eXperience concept (UX) has become more used than usability in the Human Computer Interaction (HCI) discipline and SQUARE (Systems and Software Quality Requirements and Evaluation) [1] is the standard that defines the system quality or the software quality. Nevertheless, HCI practitioners still have not come to an agreement about defining UX. Also, the standard attributes which researchers use for analyzing the UX in a specific interactive system do not exist.

For these reasons, the main aim of this research is the specification of UX based on the facets that the ISO/IEC 2010:2011 considers according to its attributes.

\section{User Experience}

The ISO DIS 9241-210:2008 [2] standard provides one of the most distinguished definitions for UX. But the following five definitions are also used considerably [3] [4] [5] [6] y [7], which were collected by E. L Law et al. in [8].

Despite the fact that the definitions presented are valid in specific contexts, they do not include aspects which should be considered when evaluating UX. In some definitions such as in [8] and [7], the interaction context is not so clear. In [3], the main topic is concerned in company aspects. Other definitions do not refer to facets such as accessibility [4], cross-cultural [5] or adaptability [6]. So, we propose the next definition of UX which covers these aspects: "User experience deals with all facts, internal as well as external facts of the user and interactive systems, which causes any feeling in the user who uses the interactive system in a specific context of use." 


\subsection{Facets and Concepts Involved in the User Experience Definition}

The facets considered in UX are still not agreed on in the scientific community or in any type of organization for standardization. Related works in this area are [9] [4]. In addition, there is other concepts which can form the UX: accessibility [10], emotional [11], communicability [12], cross-cultural [13], plasticity [14], playability [15] and dependability [16], among others. Thus, one or another facet is used according to the author and their needs in the design or evaluation process.

Our goal is not choosing the specific facets, but it is preparing the most complete set of UX facets which allows us to carry out this project.

The other goal is to determine the meaning of the most used words in the UX area. According to Oxford's dictionary (http://oxforddictionaries.com/): Property: an attribute, quality, or characteristic of something. Facet: a particular aspect or feature of something. Dimension: a measurable extent of a particular kind, such as length, breadth, depth, or height. Feature: a distinctive attribute or aspect of something.

Category: a class or division of people or things regarded as having particular shared characteristics. Attribute: a quality or feature regarded as a characteristic or inherent part of someone or something.

We are going to use these terms: Facet for determining all UX components; attributes for all features, subfeatures and attributes in the standard, and, finally, we will use dimension for measurable quality attributes considered in ISO 2502n.

\section{User Experience and ISO Standard}

The facets which are implicitly considered in the standard are specified in Table 1.

Table 1. UX facets considered in every ISO attribute.

\begin{tabular}{|c|c|c|c|}
\hline & & ISO/IEC $25010: 2011$ & UX facets \\
\hline \multirow{11}{*}{ 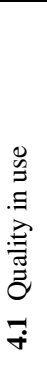 } & & 4.1.1 Effectiveness & Usability, Playability, Useful \\
\hline & & 4.1.2 Efficiency & Usability, Playability \\
\hline & \multirow{4}{*}{$\begin{array}{l}\text { 4.1.3 } \\
\text { Satisfaction }\end{array}$} & 4.1.3.1 Usefulness & Useful \\
\hline & & 4.1.3.2 Trust & Emotional, Playability, Desirable \\
\hline & & 4.1.3.3 Pleasure & Emotional, Playability, Desirable \\
\hline & & 4.1.3.4 Comfort & Emotional, Playability, Desirable \\
\hline & \multirow{3}{*}{$\begin{array}{l}\text { 4.1.4 Freedom } \\
\text { for risk }\end{array}$} & 4.1.4.1 Economic risk mitigation & Dependability \\
\hline & & 4.1.4.2 Health and safety risk mitigation & Dependability \\
\hline & & 4.1.4.3 Environmental risk mitigation & Dependability \\
\hline & \multirow{2}{*}{$\begin{array}{l}\text { 4.1.5 Context } \\
\text { coverage }\end{array}$} & 4.1.5.1 Context completeness & Usability \\
\hline & & 4.1.5.2 Flexibility & Usability and Accessibility \\
\hline
\end{tabular}


Table 1. (Continued)

\begin{tabular}{|c|c|c|c|}
\hline & ISO/IEC $25010: 2$ & 011 & UX facets \\
\hline & 4.2.1 Functional & 4.2.1.1 Functional completeness & Useful \\
\hline & suitability & 4.2.1.2 Functional correctness & Accessibility, Playability \\
\hline & & 4.2.1.3 Functional appropriateness & Accessibility, Playability \\
\hline & 4.2 .2 & 4.2.2.1 Time behavior & \begin{tabular}{|l|} 
Usability \\
\end{tabular} \\
\hline & Performance & 4.2.2.2 Resource utilization & Dependability, Accessibility \\
\hline & & 4.2.2.3 Capacity & Dependability \\
\hline & 4.2.3 & 4.2.3.1 Co-existence & Plasticity \\
\hline & Compatibility & 4.2.3.1 Interoperability & Accessibility, Plasticity \\
\hline & 4.2.4 Usability & 4.2.4.1 Appropriateness recognizability & Usability, Findable \\
\hline & & 4.2.4.2 Learnability & Usability, Playability \\
\hline & & 4.2.4.3 Operability & Usability \\
\hline & & 4.2.4.4 User error protection & Usability, Playability \\
\hline & & 4.2.4.5 User interface aesthetics & Usability, Playability \\
\hline 五 & & 4.2.4.6 Accessibility & Accessibility \\
\hline $\overrightarrow{0}$ & 4.2.5 Reliability & 4.2.5.1 Maturity & Dependability \\
\hline $\bar{z}$ & & 4.2.5.2 Availability & Dependability, Accessibility \\
\hline 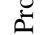 & & 4.2.5.3 Fault tolerance & Dependability \\
\hline y & & 4.2.5.4 Recoverability & Dependability \\
\hline & 4.2.6 Security & 4.2.6.1 Confidentiality & Dependability \\
\hline & & 4.2.6.2 Integrity & Dependability \\
\hline & & 4.2.6.3 Non-repudiation & Dependability \\
\hline & & 4.2.6.4 Accountability & Dependability \\
\hline & & 4.2.6.5 Authenticity & Dependability \\
\hline & 4.2.7 & 4.2.7.1 Modularity & Dependability \\
\hline & Maintainability & 4.2.7.2 Reusability & Dependability \\
\hline & & 4.2.7.3 Analyzability & Dependability \\
\hline & & 4.2.7.4 Modifiability & Dependability, Accessibility \\
\hline & & 4.2.7.5 Testability & Dependability \\
\hline & 4.2.8 Portability & 4.2.8.1 Adaptability & Accessibility, Plasticity \\
\hline & & 4.2.8.2 Installability & Plasticity \\
\hline & & 4.2.8.3 Replaceability & Plasticity \\
\hline
\end{tabular}

\section{Conclusions}

The first topic that we want to highlight is that there are attributes which are considered in more than one UX facet. So, the non-isolation of UX facets is validated.

In addition, all standard attributes are considered by some UX facets; in fact it causes a direct relation between both facets and standard attributes.

In Table 2 we can see the amount of attributes which we detected in each facet.

Despite the results of this research and as UX experts, we believe that two more facets are needed in the design or evaluation process and when other facets are applied. Both these facets could be worked in a transverse and they are called communicability [12] and cross-cultural [13]. So, we can differentiate two types of facets. The parallel facets (dependability, usability, playability, plasticity, accessibility, emotional, desirable, findable and useful) are those which can be applied in an interactive system in an individual way. And transverse facets are those which could be applied at the same time as when another facet is applied. 
Table 2. Amount of considered attributes in each UX facet. UX facets.

\begin{tabular}{lc}
\hline UX facets & Amount of attributes \\
\hline Dependability & 19 \\
Usability & 10 \\
Playability & 10 \\
Accessibility & 9 \\
Plasticity & 5 \\
\hline
\end{tabular}

\begin{tabular}{lc}
\hline UX facets & Amount of attributes \\
\hline Emotional & 3 \\
Desirable & 3 \\
Useful & 3 \\
Findable & 1 \\
\hline
\end{tabular}

Acknowledgements: The work has been partially supported by Spanish Ministry of Science and Innovation through the Open Platform for Multichannel Content Distribution Management research project (TIN2008-06228) and it has been partially supported by the University of Lleida for a pre-doctoral fellowship to Llúcia Masip.

\section{References}

1. ISO, International Software Quality Standard, ISO/IEC 25010. Systems and software engineering-Systems and software Quality Requirements and Evaluation (SQuaRE) (2011)

2. ISO DIS 9241-210:2008. Ergonomics of human system interaction - Part 210: Humancentred design for interactive systems (formerly known as 13407). ISO. Switzerland

3. http://www.nngroup.com/about/userexperience.html (última visita 4 marzo 2011)

4. Hassenzahl, M., Tractinsky, N.: User Experience - a research agenda (Editorial). Behavior \& Information Technology 25(2), 91-97 (2006)

5. Desmet, P.M.A., Hekkert, P.: Framework of product experience. International Journal of Design 1(1), 57-66 (2007)

6. Sward, D., MacArthur, G.: Making user experience a business strategy. In: Law, et al. (eds.) Procs. of the Workshop on Towards a UX Manifesto, Lancaster, UK, pp. 35-40 (2007)

7. http: / / www . uxnet. org / (last view 4 marzo 2011)

8. Lai-Chong, E., Roto, V., Hassenzahl, M., Vermeeren, A.: Kort. J. Understanding, scoping and defining user experience: a survey approach. In: Proceedings of the 27th International Conference on Human Factors in Computing Systems, pp. 719-728. ACM, NY (2009)

9. Morville, P.: Experience design unplugged. In: Kothary, N. (ed.) ACM SIGGRAPH 2005 Web Program (SIGGRAPH 2005). ACM, New York (2005); Article 10

10. W3C (2008). Web Content Accessibility Guidelines 2.0. W3C Candidate Recommendation (April 2008), http: / /www.w3 .org/TR/WCAG2 0 /

11. Leitner, G., Hitz, M., Melcher, R.: The Role of Usability in the Design and Evaluation of Dynamic Traffic Displays. In: Holzinger, A. (ed.) USAB 2008. LNCS, vol. 5298, pp. 205220. Springer, Heidelberg (2008)

12. Prates, R., de Souza, C., Simone, D.J.: Methods and tools: a method for evaluating the communicability of user interfaces. Interactions, 31-38 (2000)

13. Jiang, O., De Bruijn, O., De Angeli, A.: The Perception of Cultural Differences in Online Selfpresentation. In: Gross, T., Gulliksen, J., Kotzé, P., Oestreicher, L., Palanque, P., Prates, R.O., Winckler, M. (eds.) INTERACT 2009. LNCS, vol. 5726, pp. 672-685. Springer, Heidelberg (2009) 
14. Thevenin, D., Coutaz, J.: Plasticity of User Interfaces: Framework and Research Agenda. In: Conference on Human-Computer Interaction, INTERACT 1999, vol. 1, pp. 110-117 (1999)

15. González, J.L., Padilla, N., Gutiérrez, F.: From Usability to Playability: Introduction to Player-Centred Video Game Development Process. In: Kurosu, M. (ed.) HCD 2009. LNCS, vol. 5619, pp. 65-74. Springer, Heidelberg (2009)

16. Avizienis, A., Laprie, J.C., Randell, B., Landwehr, C.: Basic Concepts and Taxonomy of Dependable and Secure Computing. IEEE Trans. Dependable Secur. Comput. 1, 1 (2004) 